\title{
DEL TODO Y LAS PARTES \\ (COMENTARIO ACERCA DE LA GLOBALIZACIÓN Y LOS \\ PROCESOS DE INTEGRACIÓN)
}

\author{
Luis Bortesí Longhi \\ Docente.Facultad de Gencias Contables
}

\begin{abstract}
RESUMEN
Cuando pienso en integración, el primer vínculo o asociación que me viene a la memoria es la integración en matemática: se dan, en matemáticas, dos direcciones opuestas y complementarias, tal y como lo descubre la sabiduría china-taoísta en la ley de Yin-Yang: suma, multiplicación, potenciación e integración, frente a resta, división, radiación y derivación.

La integración, desde el punto de vista de las matemáticas, explica la Teoría de los Límites y constituye una base doctrinaria para comprender el concepto filosófico de la realización y la totalidad. Es así que, utilizando símbolos de geometría, se puede demostrar que el polígono más pequeño, el triángulo, al reducir el tamaño de los lados hasta el límite, se convierte en una circunferencia. Este análisis puede servir de soporte precioso para acceder a la comprensión de la dimensión de la realización intelectual y espiritual.
\end{abstract}

Palabras clave: Integración, globalización, mundialización, despersonalización.

\section{INTRODUCCIÓN}

A propósito de los procesos mundiales de integración y globalización, está precisamente en mi entrecejo una pregunta perturbadora: ¿El mundo contemporáneose está integrando o se está desintegrando? Aparentemente la tendencia moderna apunta a la realización de tratados comerciales que habrían de facilitar la integración comercial eliminando obstáculos aduaneros y administrativoburocráticos. El ejemplo más notable de integración lo encontramos en la Unión Europea que, desde el año 1950 con el tratado de Roma, aventurara una Coalición Federal que culminó con la adhesión de quince miembros importantes (hay varias incorporaciones recientes: Poloniay Hungría destacan entre ellas), aunque no todas suscribieron el Acta de aceptación de la moneda común: El Euro.

$\mathrm{Si}$ observamos detenidamente, advertiremos que la descomposición está mucho más presente que la integración: La Unión de Repúblicas Socialistas Soviéticas se atomizó fraccionando el control de dos recursos estratégicos: el petróleo y la energía atómica, que escaparon delaadministración de Moscú. El problema separatista de Chechenia representa una amenaza real hoy en día. A su vez, Yugoslavia y Checoslovaquia se han escindido. En 
España y en el Reino Unido están vivos importantes movimientos divisionistas. En Italia se corre una voz popular: "da Roma in giú non ce piú Italia", ${ }^{1}$ motivada por la gran diferencia entre el per cápita del Norte y del Sur.

Desde que se entronizó ${ }^{2}$ el Internet y afines, se habla frecuentemente de la globalización, fenómeno muy complejo $y$ avasallador que tiene polarizado al mundo entre los que lo aplauden y lo apoyan y aquellos que son sus furiosos detractores.

Para ordenar el debate, juzgo aconsejable plantear un cuestionario básico para tomarle el pulso a la globalización.

¿Se trata de un movimiento de fuerza "Centrípeta" o de una fuerza "Centrifuga"?

Es decir, hay que comprobar si estimula el centro o la periferia. Lejos de constituir un hecho de naturaleza concéntrica, la llamada globalización configura un fenómeno excéntrico, volcado completamente hacia fuera. Y el ejercicio mismo mediante Internet demuestra la tendencia a la adicción y a la diversión.

¿Qué hace un habitante del interior del país, por ejemplo de Huancavelica (Perú), con los "beneficios de la globalización"?

En tiempo paralelo al prestigio ganado por la globalización e Internet se acordó, de manera muy ligera por cierto, la teoría según la cual entramos a la "Era del Conocimiento". Y cuando yo pregunto conocimiento de qué, los interlocutores transmiten perplejidad. Sin embargo insisto

1 Más debajode Romaya no hay Italia.

2 Literalmente selapuso en el trono. y cuestiono la noción puramente técnica e infor mática del conocimiento, alejado de la cultura y de los valores más estimables que debe cuidar y priorizar la humanidad. Creo que nadie incurrirá en la ingenuidad de sostener que la globalización está satisfaciendo esa prioridad.

¿El principal resorte de la globalización es de naturaleza económica o la raíz más profunda es social o política?

Loprimero que hay que reconocer, desde mi punto de vista, es que la globalización es un hecho histórico que no deriva de la voluntad humana porque es un "signo de los tiempos”. Todos los descubrimientos célebres han modificado la vida, para bien o para mal, y en el caso que nos ocupa el aprovechamiento satelital y la cibernética le dan un impulso natural a las nuevas for mas de comunicación, son obstáculos de espacio y tiempo. Esa es la base de Internet y la globalización. Por tanto, su alcance no se circunscribe al ámbito del mercado económico y financiero, sino que su proyección no excluye ninguna área de la actividad humana.

Puesto que se trata de un hecho consumado yobviamente irreversible nadie, sensatamente, puede proclamar su oposición a la globalización porque ello equivaldría a negarse a aceptar la realidad. Sin embargo, sí tenemos que meditar y resolver una grave cuestión pendiente: No existe una autoridad -en el verdadero sentido de la palabra - que imprima orden y equilibrio en medio de la voracidad y vertiginosidad, con lo que se impone en forma avasalladora esa nueva modernidad basada en Internet y que algunos denominan 
“globalización", otros "mundialización"y,en ocasiones, es llamada "despersonalización".

\section{¿Es promisorio el porvenir del planeta?}

Si tenemos que hablar francamente, la respuesta es no. Son múltiples las razones en las que me apoyaré para demostrar mi sincero pesimismo.

Algo que descalifica a priori, sin discusión, al pretendido "progreso" moderno es el aumento desgarrador de la pobreza y de los niños que no toman desayuno. Este argumento tan sencillo como atroz basta para demostrar que la humanidad no prospera, sino recula. Si nos adentramos en un análisis más fino en otras cuestiones, considero pertinente referir me al problema general de la precariedad de las instituciones.

Comencemos por la inestabilidad en la familia: el incremento de divorcios, las tensiones, la generalizada conciencia de las parejas que prefieren uniones deliberadamente estacionales y el cada vez mayor número de jóvenes que declara su disconfor midad con el matrimonio y con la procreación. Otra institución atacada por el problema de la inestabilidad es el trabajo. Muy pocos, cada vez son menos, tienen trabajo seguro y eso provoca angustia y, en consecuencia, baja productividad y agresividad. La precariedad laboral es la responsable, además de la pérdida de la dignidad, y tal vez sea este el principal defecto que acusa la globalización. En otras palabras, tenemos que soportar la amarga paradoja: ¡A mayor progreso tecnológico, mayor índice de desocupación! Cruel ironía que nos sacude y, al parecer, nos reduce a la impotencia.
En el mundo político también está presente la garra siniestra de la precariedad o inestabilidad, visiblemente en la mayoría de los regímenes "democráticos" que son sometidos al vulgar tablero de las encuestas. $\mathrm{El}$ afecto popular es ingrato por naturaleza y la mayoría de los gobernantes se ve obligada a entablar alianzas estratégicas pasajeras, ocasionales, no doctrinarias, para tener "mayoría"; pero, evidentemente, esa condición de gobierno es de equilibrio precario. Si al cuadro anterior le añadimos la fugacidad de los periodos de gobierno, la radiografía de la inestabilidad política estará completa.

Pero todo lo anterior, no puede compararse al más dramático caso de inestabilidad: La paz mundial. Cuando vimos en la televisión la transmisión vívida y simbólicadel desplome del murode Berlín, tuvimos la ilusión de imaginar un futuro menos dicotómico y másalentador; pero nos equivocamos. La presencia de la complementariedad de los opuestos (yingyang) es una necesidad ontológica; si se violenta el cumplimiento de esta ley, se pierde el equilibrio. Estados Unidos de América no puede prevalecer manejando la hegemonía y la postura única a nivel planetario. Para desgracia de la humanidad, el símbolo del muro de Berlín tiene dos trágicas contrapartidas: Las Torres de Nueva York y los trenes de Madrid.

\section{¿Hay que adjudicarle a la globalización la responsabilidad de todos los males del mundo moderno?}

Esta pregunta sugiere el contenido del mito de Pandora y la imprudencia de Epimeteo. Sería injusto y necio aceptar un planteamiento tan reductivo, pero sostengo 
que la globalización hace más fuerte a los pocos muy fuertes y deja a su paso una lastimosa multitud de débiles $y$ desconcertados. No es un verdadero proceso de integración de las partes en un todo. Por un lado, a causa de velocidad que se le imprime a las actividades, la percepción del futuro es una pesadilla durante la vigilia. Por otro lado, percibo que los decididos y entusiastas partidarios pro globalización ignoran (o desdeñan) el siguiente precepto inspirado en pura sabiduría: "La ciencia puede descubrir lo que es cierto, pero no lo que es bueno, justo y humano". El hecho de que todo esté subordinado a la economía y a las finanzas es la raíz perversa de los males del mundo moderno. Aquí está uno de los mejores textos que he encontrado para que sirva de síntesis:

"Durante la edad oscura

La propiedad confiere el rango

La riqueza se convierte en la única fuente de virtud
La falsedad la base del éxito en la vida

La sexualidad la única fuente del placer

La religiosidad exterior se confunde con la religión interior"

Y para cerrar y nuevamente a propósito de la verdadera sabiduría, reproduzco los versos del gran maestro de Salamanca:

"un no ronpido sueño

un día puro, alegre, libre quiero

no quiero ver el ceño

vanamente severo

de a quien la sangre ensalza o el dinero"

\section{REFERENCIAS}

1. Fray Luis de León Varela. Oda a la vida retirada

2. Guenon Gallimard René. Le Règne de la Quantité et les signes des temps.

3. Pinder, John. The European Union, Oxford University Press.

4. Ulrich Beck. Qué es la globalización. Editorial Paidós, Barcelona. 